\title{
POMPEYO MAGNO Y LA CIUDAD DE ATENAS
}

\author{
LUIS AMELA VALVERDE \\ Grupo CEIPAC \\ Universitat de Barcelona \\ amelavalverde@gmail.com \\ ORCID: 0000-0002-2485-4815
}

\section{RESUMEN}

Se ha definido el mundo romano como un mundo de ciudades. No es de extrañar, pues, que en la etapa final de la República los líderes políticos intentasen tener una amplia influencia en las principales civitates. Cómo no, Atenas no fue una excepción, En este trabajo exponemos la relación entre esta ciudad y Cn. Pompeyo Magno (cos. I 70 a.C.).

Palabras ClaVE: Pompeyo Magno, Atenas, César, Contribuciones, Segunda Guerra Civil.

\section{POMPEY THE GREAT AND THE CITY OF ATHENS}

\section{ABSTRACT}

The Roman world has been defined as a world of cities. It is not surprising, then, that in the final stage of the Republic the political leaders tried to have a wide influence on the main civitates. Of course, Athens was not an exception. In this work we expose the relationship between this city and Pompey the Great (cos. I 70 B.C.)

KEYWORDS: Pompey the Great, Athens, Caesar, Contributions, Second Civil War.

\section{INTRODUCCIÓN}

La creación y el mantenimiento de una clientela provincial están directamente relacionados con la acción (y los triunfos) del político romano de turno y de la coyuntura del momento. En cualquier caso, las comunidades importantes tenían más de un patrono (Gelzer 1969: 87; Nicols 1980: 547; Brunt 1988; 398-399). ${ }^{1}$ Es el caso, por ejemplo, de Massalia (Marsella, dept. Bocas del Ródano), que había concedido esta distinción tanto a Cn. Pompeyo Magno (cos. I 70 a.C.) $)^{2}$ como a C. Julio César (cos. I 59 a.C.) (Caes. BCiv. 1, 35, 4), y de Athenae (Atenas, Ática). Ambas ciudades son citadas como ejemplo de esta política por M. H. Crawford (Crawford 1982: 176).

El presente trabajo tiene como objeto presentar la relación entre Atenas y Pompeyo desde la primera visita de éste (67 a.C.) hasta la batalla de Pharsalus (48 a.C.), dentro de nuestros trabajos sobre la clientela de este famoso político y

\footnotetext{
${ }^{1}$ El célebre orador M. Tulio Cicerón (cos. 63 a.C.) reconocía el particular honor de haber sido elegido único patrón de Capua (Cic. Sest. 9).

2 Vid: L. Amela Valverde, "Pompeyo y su influencia en la Galia Transalpina: el caso de Massalia", Myrtia 31 (2016), 141-166
} 
general. ${ }^{3}$ Ha de destacarse que esta importante ciudad griega, junto con la Liga Tesalia, fueron los dos únicos estados de importancia que se libraron de la provincialización de Grecia en el año 146 a.C.

\section{LA PRIMERA VISITA}

Pompeyo limpió el Mediterráneo Occidental de piratas en el tiempo récord de cuarenta días (Plut. Pomp. 26, 7). Después de una corta pero imprescindible estancia en Roma, volvió a embarcarse en Brindisi (Plut. Pomp. 27, 1-3). A pesar de estar presionado por el tiempo (Plut. Pomp. 27, 4), pues tenía que continuar con la campaña contra los piratas en el Mediterráneo Oriental, Pompeyo hizo una escala en Atenas (Plut. Pomp. 27, 4-5. Cf. Zonaras, 10, 3). Indudablemente, aquí esperaría encontrar toda o parte de las fuerzas navales aliadas destinadas a la continuación de la campaña contra la piratería (Greenhalgh 1980: 94).

M. Hoff considera que Pompeyo, desde Brindisi, sólo hizo escala en Atenas antes de emprender la fase final de la campaña contra los piratas (Hoff 2002: s.p.). Pero muchos investigadores consideran que Pompeyo se detuvo así mismo en Rodas (Ormerod 1924: 239; Ooteghem 1954: 176; Carcopino 1968: 87; Flacelière y Chambry 1973: 296 y 302; Leach 1978: 72; Kallet-Marx 1995: 318; Amela 2003b: 113). Aquí se demoró en conversar con la «mayor atracción turística», en palabras de K. Kallet-Marx (Kallet-Marx 1995: 318), de la isla: el filósofo Posidonio, aunque las fuentes consideren que este encuentro se efectuó

3 Vid: L. Amela Valverde, "El desarrollo de la clientela pompeyana en Hispania", SHHA 7 (1989), 105-117; “La clientela de Cneo Pompeyo Magno en Hispania”, Historia y Vida 270 (1990), 90-97; “La amonedación pompeyana en Hispania. Su utilización como medio propagandístico y como reflejo de la clientela de la gens Pompeia", Faventia 12-13 (1990-1991), 181-197; “Numidia y la clientela pompeyana. La acción de los políticos de la República Romana en el extranjero", Iberia 3 (2000), 253-264; "La turma Salluitana y su relación con la clientela pompeyana”, Veleia 17 (2000), 79-92; “La clientela de Cneo Pompeyo Magno en Hispania”, Historia 16297 (2001), 64-73; "Inscripciones honoríficas dedicadas a Pompeyo Magno", Faventia 23/1 (2001), 87-102; "El nomen Pompeius en Hispania: Algunos aspectos críticos", Emerita 69 (2001), 241-262; "La Galia Cisalpina y la clientela de Pompeyo Magno", Polis 14 (2002), 51-78; "El nomen Pompeius en la numismática hispánica", Fortunatae 13 (2002), 9-30; "Nota sobre una inscripción de Tasos (AE 1994 1540)", Pyrenae 33-34 (2002-2003), 373-376; Las clientelas de Cneo Pompeyo Magno en Hispania, Barcelona, 2003; "Pompeyo Magno y la guerra sertoriana: la constitución de una clientela", BMZ 17 (2003), 105-131; "Las concesiones de ciudadanía romana: Pompeyo Magno e Hispania”, AC 73 (2004), 47-107; “Caes. BCiv. 2, 18, 7. Una nota sobre la obra de Eilers Roman Patrons of Greek Cities", Veleia 21 (2004), 303-309; "Navarra, Roma e Hispania: Pompeyo", en Navarra en la Antigüedad: Propuesta de Actualización (Pamplona, 2006), 137-166; “El epígrafe dedicado a Cn. Pompeyo Magno en la ciudad de Demetrias (IG IX 2, 1134). El reflejo de la política romana en una ciudad de provincias", SEBarc 13 (2015), 25-33; "Pompeyo Magno y la Galia Transalpina. La guerra sertoriana", Helmántica 204 (2019), 9-52. 
tras la finalización de la Tercera Guerra Mitridática (74-63 a.C.), ${ }^{4}$ aunque nada impide que Pompeyo estuviera anteriormente en Rodas (Ooteghem 1954: 176).

La vista de Pompeyo no tenía nada de extraordinario. Multitud de magistrados romanos destinados a la provincia de Asia recalaban en esta ciudad. ${ }^{5}$ En el transcurso de la visita. Pompeyo recibió unos elogios hiperbólicos (Carcopino 1968: 87). He aquí el testimonio de Plutarco: «Allí [en Atenas], él [Pompeyo] subió a ofrecer un sacrificio a los dioses y arengó al pueblo. Saliendo inmediatamente después, él pudo leer algunas inscripciones en su honor, formada cada una de un solo verso, uno en el interior de la puerta de la ciudad: "En cuanto sabes que eres hombre, tanto más eres un dios", y otra en el exterior: “Te esperamos, nos prosternamos, te vimos, somos tú escolta"» (Plut. Pomp. 27, $5) .6$

Como bien señala K. Kopij, si bien aunque estas frases fueran producto de la imaginación del escritor de Queronea, ofrecen una visión similar a las inscripciones honorarias típicas dirigidas a Pompeyo, ya que jugaron un papel similar. En primer lugar, estaban dirigidas al propio Pompeyo. Son el tiempo, si no fueron destruidas demasiado rápido, estas frases podían convertirse fácilmente en mensajes de propaganda a favor del personaje en cuestión. Sin duda, este tipo de inscripciones fueron muy comunes en el mundo antiguo, como ejemplifica el caso de la ciudad campana de Pompeii, pero raramente se han conservado. Es posible que algunas de ellas hayan sido inspiradas por personas que perteneciesen a los círculos de del personaje protagonista de estos mensajes. Probablemente, desempeñaron un papel similar al de los carteles de hoy en día, excepto que debido a su singularidad en una escala mucho más pequeña; éstos, a su vez, fueron uno de los medios de propaganda masiva más utilizados en el siglo XX (Kopij 2017: 250-251).

La visita a la ciudad más famosa de Grecia fue corta aunque oportuna (Heftner 1995: 201). Los atenienses sabían lisonjear la vanidad de Pompeyo, el cual, sin embargo, al mismo tiempo, tenía cierta aprensión ante los honores (Heftner 1995: 202).

4 Tres de las fuentes (Cic. Tusc. 2, 61. Plin. NH 7, 112. Plut. Pomp. 42, 10) señalan que la entrevista de Posidonio y Pompeyo fue realizada tras este conflicto, pero la cuarta (Str. 11, 1, 6) parece situar el encuentro durante la guerra contra la piratas.

${ }^{5}$ De esta forma, tenemos los ejemplos de Q. Mucio Escévola el augur (cos. 117 a.C.) ca. el año 120 a.C. (Cic. Fin. 1, 8, 9), M. Antonio (cos. 99 a.C.) ca. el año 102 a.C. (Cic. De or. 1, 82; 2, 3), M. Licinio Craso el orador (cos. 95 a.C.) en la última década del siglo II a.C. (Cic. De or. 1, 45; 3, 75), L. Gelio (cos. 72 a.C.) en el año 93 a.C. (Cic. Leg. 1, 53), L. Cornelio Sila (cos. I 88 a.C.) a su vuelta hacia Italia (Nep. Att. 4, 2. Plut. Sull. 26), M. Tulio Cicerón (cos. 63 a.C.) en los años 51 y 50 a.C. (Cic. Att. 5, 10, 2; 5, 11, 14; 6, 1, 26; Fam. 2, 8. Cf. Tusc. 5, 22).

6 Como señalan Flacelière y Chambry 1973: 197 n. 2, estos dos monostichoi (versos independientes) son tetrámetros trocaicos catalécticos, que para Aguilar y Pérez Vilatela 2004: 167 no son de muy bella factura y están cargados de adulación, que dan medida de lo que era Atenas desde el punto de vista político en este momento de su historia. 
Si bien Pompeyo fue ensalzado desde la esfera humana a la divina, no ha de considerarse que se le admirase ni ahora ni posteriormente como un dios, sino más bien bajo la protección particular de una divinidad (Classen 1963: 332; Heftner 1995: 202), aunque no todo el mundo está de acuerdo en esta solución, ya que estos versos podían presentar una connotación en forma específica de referencia divina (Edwards 1997: 123). M. Hoff señala que si los honores proferidos a Pompeyo fueron divinos (isotheoi timai, como se infiere de la

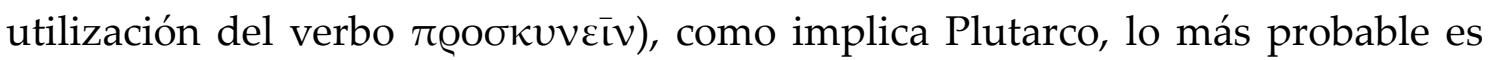
que estos fueron rechazados de manera cortés (Hoff 1989a: 271, 2005: 331).

Pompeyo llegaría a El Pireo, el puerto de Atenas, y, desde allí, se dirigiría a la ciudad, donde ofreció un sacrificio (quizás en la Acrópolis) (Edwards 1997: 122; Morales 2015: 235) y se dirigió al Pueblo (dêmos). Es muy posible que el discurso de Pompeyo se pronunciara en una reunión apresuradamente convocada en la ekklêsia, y se daría desde la bêma en el Ágora. ${ }^{7}$ A destacar que este es uno de los pocos actos que se pueden relacionar a Pompeyo con los cultos locales durante sus estancias en Oriente (Santangelo 2007: 232 n. 20). H. P. Collins dijo que la visita de Pompeyo en Atenas en esta ocasión fue "un desfile de su piedad" (Collins 1953: 102).

Posteriormente, Pompeyo salió de Atenas hacia sus barcos que estaban anclados en el puerto de El Pireo. Presumiblemente, dejaría la ciudad a través del Dípilon o Puertas del Pireo, donde pudo leer las frases transmitidas por Plutarco, que seguramente habrían sido pintadas (Hoof 2002: s.p., 2005: 328; Morales 2015: 236; Heijnen 2018: 84).

La causa del entusiasmo de la población ateniense con Pompeyo provenía del hecho de que éste iba a acabar con la amenaza protagonizada por la piratería, pronóstico avalado por el éxito inmediato alcanzado en el Mediterráneo Occidental (Habicht 2000: 364; Hoff 1989a: 271; 2002: s.p.; Edwards 1997: 120-121; Amela 2003b: 112). No era para menos, puesto que después del saqueo del puerto y de la ciudad efectuado por L. Cornelio Sila (cos. I 88 a.C.) en el marco de la Primera Guerra Mitridática (89-85 a.C.), en el año 86 a.C. (Cf. Plut. Sull. 13-14), Atenas había entrado en graves dificultades en todos los campos.

La piratería afectaba directamente a la recuperación económica de la ciudad. Los piratas habían saqueado Delos, dependencia ateniense, en el año 69 a.C. (Phlegon, FGrHist 257 F 12-13) y, en el mismo golfo Sarónico, los templos de: Asclepio en Epidauro, de Hera en Argos y el de Poseidón en el Istmo habían sufrido sus ataques (Plut. Pomp. 24, 6). Estos datos muestran que la misma Atenas (o sus alrededores) podía ser objeto de un ataque de estas características (Hoff 2002: s.p.).

\footnotetext{
${ }^{7}$ Hoof 2002: s.p., 2005: 328 n. 5 que recuerda que el bêma es citado cuando el filósofo Atenión pronunció su discurso a favor de Mitrídates el año 88 a.C. (Athenaeus 5, 212 e-f). Morales 2015: 235-236.
} 
Atenas no estuvo sola entre las ciudades orientales que efectuaron homenajes a Pompeyo. Gran número de comunidades griegas recordaron en inscripciones sus acciones contra los piratas y contra Mitrídates VI del Ponto (120-63 a.C.), algunas ciertamente exageradas. ${ }^{8}$ En Delos, dos inscripciones atestiguan la existencia de una asociación de Pompeiastai (I.Delos 1641 y 1797), que en analogía con otras asociaciones de la isla, ${ }^{9}$ debe referirse a un grupo religioso devoto de Pompeyo (Edwards 1997: 123). Evidentemente, la eliminación de la piratería no sólo aseguraba la integridad física de la ciudad sino también su suministro de alimentos, a la par que albergaba la esperanza de una nueva prosperidad (Edwards 1997: 125).

Pudiera suponerse que esta demostración de admiración por el pueblo ateniense hacia Pompeyo sería de carácter popular, a juicio de lo relatado por Plutarco. Pero no hay que dejarse engañar. A su vuelta a Roma después de conocer la muerte de Mitrídates, Pompeyo hizo de nuevo escala en Atenas (62 a.C.), en donde hizo entrega de un donativo de cincuenta talentos para la reconstrucción de la ciudad (Plut. Pomp. 42, 11). ${ }^{10}$ Este dato nos hace reflexionar de la veracidad de las palabras de Plutarco. No tanto de la existencia y contenido de los grafitos atenienses, sino de la fecha en que éstos fueron realizados. Muchos de los epígrafes conservados en las comunidades griegas son claramente posteriores a las campañas militares de Pompeyo, al mencionar su tercera aclamación como imperator. ${ }^{11}$

Ciertamente, es una premonición que antes de finalizar las operaciones militares se celebrara el resultado, aunque no se dudaba en ningún momento del triunfo. Pero, curiosamente, Plutarco (con el resumen de Zonaras) es el único autor que recoge tanto los grafitos en su honor como el donativo de Pompeyo a Atenas. Si nos preguntamos de dónde sacó Pompeyo el dinero para esta generosa donación, la respuesta inmediata es del botín procedente de sus campañas en Oriente.

Por supuesto, Pompeyo podía haber obtenido la cantidad cedida a Atenas en la guerra contra Q. Sertorio (pr. 83 a.C.) en Hispania (82-72 a.C.) o incluso antes durante la Primera Guerra Civil (83-81 a.C.). Pero no parece posible que durante la campaña contra los piratas Pompeyo dispusiera de tanto dinero, fuese de su fondo privado o del erario público (la lex Gabinia le autorizaba a ello, aunque tal fin evidentemente habría sido un claro abuso), puesto que éste

${ }^{8}$ Vid: Amela 2001: 88-93.

9 Sobre estas asociaciones en Delos, vid: Müller 2017: 96.

10 Thompson 1941: 222 señaló que este donativo fue realizado para la restauración de los edificios públicos, mientras que Hoff 1989a: 271, 2013: 569; Melfi 2010; 24, 2016: 156 para la reconstrucción de monumentos.

${ }^{11}$ En Demetriae (IG IX 2 1134), Ilium (AE 1990940 = SEG XLVI 1565. IGRR IV 198 = IK 3 74), Miletopolis (AE 1907183 = IK 224 = ILS 9459), Miletos (Milet I, 7, 253), Mytilene (IG XII $202=$ IGRR IV $54=$ ILS 8776 = Syll. ${ }^{3}$ 751) y Soli-Pompeiopolis (AE 1888106 = IGRR III 869). Incluso se tiene atestiguada una cuarta en Argos (AE 1920 81). 
último no estaba precisamente en un momento de prosperidad. Por ello, cabría preguntarse si Pompeyo recibió estos elogios de los atenienses durante su segunda visita a Atenas, esto es, en el año 62 a.C., vid infra, cuando también efectuó el donativo de cincuenta talentos, motivo más que suficiente para recibir tales elogios. Quizás Plutarco dividió ambos acontecimientos para que no diera la impresión que uno derivaba del otro, esto es, la dádiva había ocasionado la aparición de los grafitos, al ser posiblemente hechos independientes. El restablecimiento de la economía de Atenas dependía de su comercio marítimo a través de El Pireo (Hoff 2002: s.p.), que obedecía a la eliminación del peligro que suponía la piratería, que muchas poblaciones de Atenas vecinas habían sufrido (Day 1942: 129). Si además se obtenía un donativo de cincuenta talentos (destinados no por casualidad a la infraestructura portuaria, vid infra), mucho mejor.

\section{LA SEGUNDA VISITA}

En la primavera del año 62 a.C., tras la finalización de la Tercera Guerra Mitridática y el restablecimiento de la pax romana en el Oriente helenístico, Pompeyo comenzó su vuelta triunfal a Italia, efectuando diversas paradas en ruta (Kallet-Marx 1995: 331; Hoff 2002: s.p.). Plutarco cita a éstas de Oriente a Occidente, así como los beneficios realizados por Pompeyo (Plut. Pomp. 42, 711). He aquí el texto de Plutarco:

«Cuando (Pompeyo) hubo puesto en orden y regulado los asuntos de allí [Asia], prosiguió su viaje con más solemnidad. Llegado a Mitilene, dio la libertad a la ciudad en consideración a Teófanes, y asistió al concurso tradicional de los poetas, que tomaron por único tema sus propias gestas. Encantado de la belleza del teatro, hizo dibujar el aspecto y el plano, con la intención de levantar en Roma uno igual, pero más grande y más magnífico. Llegado a Rodas escuchó a todos los sofistas y dio a cada uno de ellos un talento. Posidonio incluso dejó escrito la conferencia que pronunció en su presencia para refutar al retórico Hermágoras a propósito de su tesis de la Búsqueda Universal. En Atenas, él también se comportó de manera parecida con los filósofos, e hizo una donación a la ciudad de cincuenta talentos para su restauración ...»

Puede observarse un contraste evidente entre ambas visitas. Si en la primera Pompeyo se dedicó a efectuar actividades de carácter religioso y cívico, el segundo tiene más visos de turismo cultural: certamen de poesía en Mitilene (Plut. Pomp. 42, 8), retórica en Rodas (Plut. Pomp. 42, 10) y filosofía en Atenas (Plut. Pomp. 42, 11), destacando cada ciudad en el género que presenció Pompeyo (Morales 2015: 236-237).

El propósito de Pompeyo en estas donaciones tanto públicas como privadas era, de acuerdo con Plutarco, aumentar su reputación, vid infra. Esto es cierto, pero no toda la verdad. Indudablemente, Pompeyo estaba, en palabras 
de M. Hoff, "sembrando la semilla de la lealtad" (Hoff 2002: s.p.) ${ }^{12}$ hacia su persona como se demostrará en la posterior guerra civil.

Plutarco no recuerda como los atenienses usaron los cincuenta talentos,

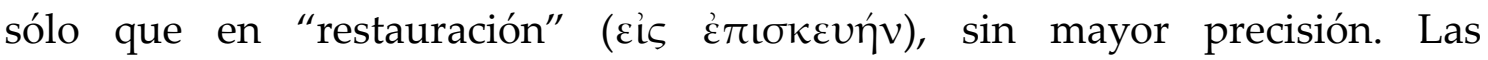
reparaciones a las que alude el autor griego hace referencia ciertamente han de estar relacionadas con los daños causados por Sila durante el sitio y saqueo de la ciudad de Atenas y el puerto de El Pireo, ${ }^{13}$ casi un cuarto de siglo antes. Este hecho implica que al menos durante aproximadamente veinticinco años muchos de los edificios y monumentos de la ciudad no fueron reconstruidos ni reparados, e incluso que algunos estaban tan dañados que fueron dejados definitivamente al abandono (Hoff 1997: 43, 2002: s.p., 2005: 332; Habicht 2000: 363). Este último caso fue el Pompeion (nada que ver con Pompeyo Magno), edificio público ubicado en el Cerámico construido ca. el año 400 a.C., y que no volvería a ser restaurado y utilizado en su propósito inicial hasta el siglo II d.C. (Day 1942: 185; Hoff 1997: 41; Habicht 2000: 338).

El beneficio otorgado por Pompeyo es el primero recordado en relación con las reparaciones de la ciudad (Habicht 2000: 364: Hoff 2002: s.p., 2005: 332). Por lo menos parte de los fondos de Pompeyo fueron aparentemente utilizados para reconstruir la infraestructura comercial de la ciudad. Un catálogo fragmentario de reparaciones a los santuarios (IG II 1035 1. 47) menciona un "Deigma de Magnus"; generalmente se sobreentiende que el apelativo "Magnus" ha de referirse forzosamente a Pompeyo (Day 1942: 128-129 y 149; Ooteghem 1954: 269; Oliver 1972: 191; Geagan 1979: 375; Rawson 1985: 45; Hoff 1989a: 271, 1989b: 2, 2002: s.p., 2005: 333, 2013: 569; Heftner 1995: 294; Edwards 1997: 126; Grigoropoulos 2005: 63 y 254, 2016, 247; Borg 2011: 218; Toher 2014: 128; Dickenson 2015: 747; Morales 2015: 225 y 237; Heijnen 2018: 84). ${ }^{14}$ Esto no significa que todo el montante dado por Pompeyo se destinase a este único fin, como el de César, vid infra, a la Ágora romana, como se ha defendido (Dickenson 2015: 747-748). Simplemente, es la única evidencia de la que tenemos constancia en la que las sumas de ambos personajes parece que se emplearon en estos menesteres.

12 Geagan 1979: 377 señaló que esta lealtad quedaría reflejada no sólo en el donativo de cincuenta talentos, sino en una revisión de la constitución ateniense, teoría que hoy en día ha sido rechazada, así como cualquier cambio constitucional durante el siglo I a.C.

${ }^{13}$ Cuartel general de las fuerzas pónticas (App. Mith. 29. Paus. 1, 20, 5. Plut. Sull. 11, 3), que Sila mandó arrasar.

${ }^{14}$ Day 1942: 145-146 señala que en contra de esta identificación se ha aducido que el nombre Magnus aparece en inscripciones atenienses de los siglos II a.C. (IG II ${ }^{2} 3780$ ) y II d.C., y que el «Magno» mencionado sería un rico ateniense, de quien, por otra parte, nada se conoce. Además, el empleo de un único nombre en la inscripción indica que el individuo mencionado era excepcionalmente bien conocido a los atenienses, y el único que reúne tales características es Pompeyo. 
Como indica M. Hoff (Hoff 1989: 2 n. 9, 2002: s.p.), el término deigma es frecuentemente traducido con el significado de 'bazar', pero esto es bastante vago. Deigma es derivado del verbo deiknumi, que sugiere un lugar donde los bienes pudieran ser exhibidos. La evidencia literaria parece colocar el Deigma a la derecha en la línea de costa del Pireo, quizás sobre un muelle (Dem. Or. 35, 29. Xen. Hell. 5, 1, 21). Debido a su íntima proximidad al puerto y a las dársenas, el Deigma podía haber operado como un área específicamente definida, quizás arquitectónica, donde muestras de las mercancías directamente de las embarcaciones amarradas podían ser exhibidas y vendidas (Hoff 2002: s.p., 2005: 333 n. 27). Sea como fuere, el objetivo era ayudar a restablecer las infraestructuras comerciales de la empobrecida ciudad así como reafirmar su apertura al tráfico de mercancías (Borg 2011: 218; Grigoropoulos 2016: 256). Así mismo, H. S. Robinson ha sugerido que el dinero del donativo de Pompeyo se podría haber utilizado en la construcción de la Torre de los Vientos (Robinson 1984: 424), un horologium situado en el Ágora romana. Esta teoría ha sido contestada por Chr. P. Dickenson, sobre la base de que, en primer lugar, parece ser que existen buenas razones para pensar que la Torre del Viento fue construida en el siglo II a.C., y que, en segundo lugar, la suma de cincuenta talentos parece ser demasiado alta para la edificación de este monumento, si la misma cantidad fue empleada para la construcción de todo el Ágora romana (pues este autor considera que el donativo de César se utilizó de manera íntegra aquí) (Dickenson 2015: 747 n. 92). La intervención de Pompeyo se asemejaba más a la de un monarca helenístico que a la de un general romano (Leach 1978: 101; Eilers 2002: 98 n. 67; Amela 2003b: 182; Heijnen 2018: 85). La nobilitas romana ( $\mathrm{y}$, en menor, medida, los reyes de los estados periféricos) vinieron a sustituir a los soberanos de los grandes estados helenísticos (Habicht 2000: 363364; Hoff 2013: 569; Heijnen 2018: 102). Como señala Plutarco, tras la donación de cincuenta talentos efectuada por Pompeyo a Atenas, «Tenía [Pompeyo] la esperanza de poner pie en Italia como el más ilustre de los hombres ... » (Plut. Pomp. 42, 11). La palabra clave es: evergetismo (Heijnen 2018: 85 y 102). César hará otro tanto en el año 50 a.C. (Cic. Att. 6, 1, 25). Así pues, Atenas es la primera ciudad provincial (conocida) que se beneficia de la emulación entre principes que hasta entonces había estado reservada únicamente a Roma (Ferrary 1997: 201). Se ha propuesto que el patronato romano llegó a incluir la obligación de suministrar a las ciudades "clientes" donaciones de dinero, monumentos y espectáculos públicos, pero esto no es cierto, como ha indicado Cl. Eilers (Eilers 2002: 98). Casi todos los patrones de ciudades griegas eran senadores romanos, la mayoría gobernadores provinciales, y sus clientes eran principalmente las ciudades que se encontraban en las provincias que gobernaban. Individuos de esta clase eran raramente generosos desde el punto de vista material hacia aquellos que gobernaba, y en los pocos casos en que lo era, no existe evidencia que actuaran como patroni de estas comunidades, o que fuesen considerados como patronos debido a su generosidad. Efectivamente, 
sería sorprendente si lo fueran, por lo menos en el contexto de sus deberes oficiales, cuando el dinero y los recursos tendían a fluir en dirección contraria.

Como puede apreciarse, la importancia de los magistrados romanos en Oriente, aunque fuese en una ciudad libre (al menos, desde el punto de vista teórico) como Atenas, comienza a marcar la futura tendencia en época imperial. No ha de caer en saco roto que Pompeyo fue un antecesor de varias de las medidas adoptadas por el emperador Augusto (27 a.C.-14 d.C.) después de su triunfo en Actium (31 a.C.). ${ }^{15}$ Pero es de notar que en las importantes ciudades libres y federadas como Atenas y Rodas no aparezca ningún patrón romano (Ferrary 1997: 211). Como señala $\mathrm{Cl}$. Eilers, ningún patrono está atestiguado en Atenas, a pesar de la abundante epigrafía encontrada en la ciudad. Es posible que su comprensión de su propia historia o de su importancia les hizo resistir a la tendencia general. En cualquier caso, los patronos parecen menos comunes entre las ciudades de la Grecia continental que en la provincia de Asia o las islas del Egeo, lo que puede indicar la existencia de una tradición local. Todo esto puede con seguridad ser dicho que muchas ciudades son conocidas por tener patronos (Eilers 2002: 148-149). Se desconoce si los atenienses reconocieron alguna vez la generosidad de Pompeyo elevándole estatuas, pues no se ha encontrado ningún testimonio de ello. Así mismo, es muy dudoso que si existieran perduraran después de la batalla de Pharsalus (48 a.C.) (Hoff 2002: s.p.). Curiosamente, sí se conocen estatuas dedicadas a Sex. Pompeyo (pr. 121 a.C.?) (AE 1910177 = IG II $4100=$ Syll. $^{3}$ 701) y a Cn. Pompeyo Estrabón (cos. 89 a.C.) (AE $1908199=$ IG II ${ }^{2}$ 4101), ${ }^{16}$ abuelo y padre respectivamente de Pompeyo. Pero existen dudas de cuándo se efectuaron estas dedicatorias, pues varios investigadores consideran que fueron efectuadas con ocasión de la visita de Pompeyo en el año 62 a.C. (Kallet-Marx 1995: 52 y n. 39 y 203; Hoff 2002: s.p., 2005: 332; Heijnen 2018: 84). ${ }^{17}$ Pero, a nuestro entender, durante la visita de Pompeyo a Atenas, éste pudo admirar las estatuas de sus antepasados (Groebe 1909: 405; Ooteghem 1954: 34; Krumeich 2014: 145), sin tener relación directa con su presencia en la ciudad.

${ }_{15} \mathrm{Vid}$, p.e., G. A. Lehmann, "Der Beginn der res gestae des Augustus und das politische exemplum des Cn. Pompeius Magnus", ZPE 148 (2004), 151-162. F. Hurlet, "Auguste et Pompée", Athenaeum 94 (2006), 467-485; “De Pompée à Auguste: les mutations de l'imperium militiae. 1. Les réalités institutionnelles", en Cassius Dion: nouvelles lectures. Volumen II (Bordeaux, 2016), 581593. C. Koehn, "Pompeius, Cassius und Augustus. Bemerkungen zum imperium maius", Chiron 40 (2010), 301-322. F. J. Vervaet, "Arrogating despotic power through deceit: the Pompeian model for Augustan dissimulatio", en Private and Public Lies. The Discourse of Despotism and Deceit in the Graeco-Roman World (Leiden-Boston, 2010), 133-166.

${ }^{16}$ Dumont 1871: 21 n. 2 señala que un Cn. Pompeyo fue efebo en Atenas en un año en que lo más seguro Pompeyo Estrabón tendría 18 años. No identifica al personaje, pero la impresión es que identifica a ambos personajes. No he podido averiguar más sobre ello.

${ }_{17}$ Únicamente se sabe con certeza que Sex. Pompeyo fue gobernador de Macedonia. De Pompeyo Estrabón se ha supuesto lo mismo al aparecer su estatua en Atenas, pero Brennan 2000: 747; Díaz Fernández, 2015, 426 no lo hacen figurar en los fasti provinciales. 


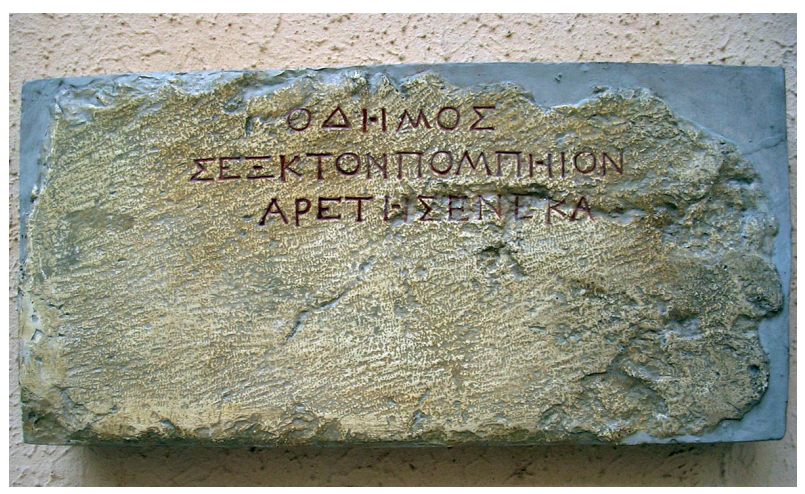

Inscripción dedicada a Sex. Pompeyo en Atenas (AE $1910177=$ IG II ${ }^{2} 4100$ = Syll. ${ }^{3}$ 701)

Finalmente, cabe destacar la suposición tradicional de que Pompeyo pudo haber sido iniciado en los Misterios de Eleusis ${ }^{18}$ durante su visita del año 62 a.C., como otros políticos romanos, que iban a la ciudad de visita o a tomar lecciones de filosofía (Kallet-Marx 1995: 203; Hoff 2002: s. p.). Como los ritos de iniciación tenían lugar a finales de septiembre, es posible que Pompeyo podía haber coordinado su viaje hacia Italia con una parada en Atenas midiendo el tiempo para poder coincidir con el ritual (Hoff 2002: s.p., 2005: 332). Pero no existe ninguna evidencia a favor de este hecho (Amela 2005: 17; Heijnen 2018: 84).

\section{LA EMISIÓN KROLL 129}

J. H. Kroll, en su estudio sobre las monedas aparecidas en el ágora de Atenas, hace referencia a una fracción de bronce, AE 2 (Kroll 129), a la cual considera una hemidracma, perteneciente a su Periodo IV (86-10s a.C.), concretamente al Periodo IVA, que fecha entre los años 70s-40s a.C., ${ }^{19}$ que relaciona con la actividad Pompeyo. Esta emisión presenta en el anverso un delfín y un tridente mientras que en el reverso figura la leyenda A- $\Theta E$ con un Plemochoe con espigas de trigo en cada asidero ${ }^{20}$; todo dentro de una corona de espigas de trigo.

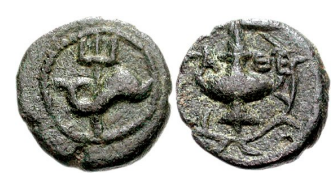

${ }^{18}$ Sobre este culto, Vid: G. E. Mylonas, Eleusis and the Eleusinian Mysteres, Princeton, 1961. R. G. Wasson, A. Hofmann y C. P. Ruck, The Road to Eleusis. Unveiling the Secret of the Mysteries, Berkeley, 2008. M. B. Cosmopoulos, Bronze Age Eleusis and the Origins of the Eleusinian Mysteries, Cambridge, 2015.

${ }_{19}$ Hoover 2014: 497 clasifica esta moneda como HGC 4 1723, una denominación C según su propia escala de valores, acuñada $c a$. los años 80-40 a.C. Hoover 2014: 467 se hace eco de la opinión de J. H. Kroll (sin citarlo) de que la presente emisión fue acuñada en Atenas en el año 62 a.C. con motivo de la presencia de Pompeyo en la ciudad.

${ }^{20}$ Aunque, ciertamente, nosotros no las distinguimos. 
Moneda de bronce Kroll 129 = Svoronos 107. 1-821

Se encontraron 26 de estas piezas en el ágora de Atenas, con un diámetro de 14-17 mm, y un peso medio de $4.09 \mathrm{~g}$ (en 15 ejemplares) (Kroll 1993: $98 \mathrm{y}$ 328). El tridente y delfín representan a Poseidón (Stevenson 1964: 352 y 811), cuya cabeza probablemente habría sido colocado en el anverso para no confundirse fácilmente con la cabeza de Zeus (Kroll 1993: 99). Este es el único tipo de moneda ateniense pre-imperial que se refiere a Poseidón. ${ }^{22}$ El plemochoe en el reverso se ajusta a la rutinaria práctica de diseño del Periodo IV de la media unidad de AE-2 con tipos eleusinos (Kroll 1993: 99). Poseidón podría haber sido elegido como motivo para el anverso debido a sus conexiones con Eleusis: esta divinidad era el antepasado de la familia de los Eumólpidas (los cuales oficiaban precisamente los Secretos de Eleusis), y tenía además un templo en las afueras del santuario de Deméter y Kore (Kroll 1993: 99). Debemos destacar la enorme importancia de los Misterios de Eleusis durante toda la historia de Grecia, que prosiguió durante la dominación romana.

Después de la toma de la ciudad de Atenas por Sila en la primavera del año 86 a.C., el carácter de la amonedación de bronce ateniense fue abruptamente transformado: se abandonó la iconografía del Zeus fulminador (AE 2) del Gobierno anterior (Kroll 97), y Atenas comenzó a acuñar grandes y pesados AE 1, equivalentes a dracmas (Kroll 115-126), que se convirtieron en la principal unidad de la ciudad hasta el advenimiento de la amonedación imperial griega en el siglo II d.C. (Kleiner 1975: 14; Kroll 1993: 81)

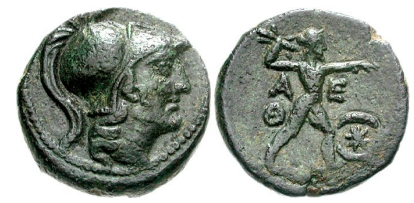

Moneda de bronce Kroll 97

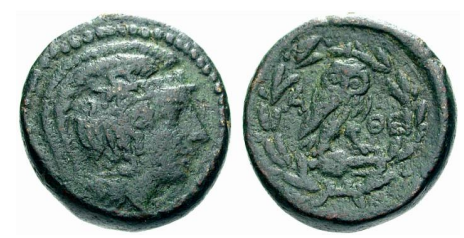

Moneda de bronce Kroll 115

En adición a estas emisiones regulares, la unidad de AE 1 fue acuñada en dos excepcionales emisiones con tipos eleusinos (Kroll 116-117). Ambas fueron acuñadas a principios del Periodo IVA e implica una excepcional fastuosidad en

\footnotetext{
${ }^{21}$ N. Svoronos, Les monnaies d'Athènes, completado por B. Pick, Munich 1923-1926. Reimpreso con traducción del texto y corpus como Corpus of the Ancient Coins of Athens, Chicago 1975

${ }^{22}$ Hoover 2014: 467 califa a este anverso de "inesperado".
} 
celebrar los Misterios de Eleusis en este momento (Kleiner 1975: 14; Kroll 1993: 82). Plutarco (Plut. Sull. 26, 1) señala que Sila se inició en los Misterios de Eleusis a su vuelta a Atenas en el año 84 a.C., lo que podría explicar estas amonedaciones (Kroll 1993: 82).

J. H. Kroll considera por comparación la aparición igualmente sin precedentes del dios Dioniso, que fueron acuñados para halagar a Marco Antonio (cos. I 44 a.C.) durante su residencia en Atenas en la década de los años 30s (Kroll 140-142 y 144), al identificarse éste con dicha divinidad (Dio Cass. 47, 39, 2. Sen. Suas. 1, 6-7. Socrat. Rhod. Apud Athenaios 4, 148 B-C. Zon. 10, 23) (Kroll 1993: 85 y 103-104), considera que es posible que la presente emisión de moneda fraccionaria ateniense se circunscriba al año 62 a.C., cuando Pompeyo visitó Atenas en su regreso triunfal a Roma después de sus victorias en Oriente (Kroll 1993: 99).

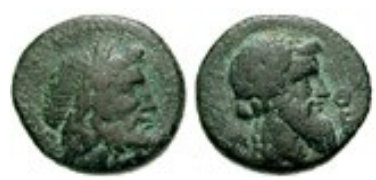

Moneda de bronce Kroll 144

Ha de tenerse en cuenta que Pompeyo Magno fue póstumamente llevado a la apoteosis como Neptuno por su hijo menor Sexto Pompeyo (cos. desig. 33 a.C.), quien se llamaba a sí mismo «hijo de Neptuno» (App. BCiv. 5, 100. Auct. Vir. Ill. 3, 84, 2. Dio Cass. 48, 19, 2; 48, 48, 5. ${ }^{23}$ Flor. 2, 18, 3. Plin. NH 9, 55), e incluso Neptunius dux (Hor. Ep. 9, 7-8), en referencia a la victoria naval que su padre había logrado contra los piratas en el año 67 a.C. A destacar que en el año 44-43 a.C. Sexto Pompeyo acuñó denarios (RRC 483/1-2) con el retrato de Pompeyo Magno en que el letrero lo identifica como Neptuno, es decir, como señor de los mares, acompañado por los símbolos del delfín y el tridente (RRC 483/1-2) ${ }^{24}$ (Kroll 1993: 99 n. 201), los atributos de la deidad marina.

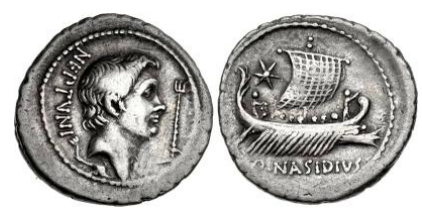

Denario de plata RRC 483/2

Por supuesto, se trataba de propaganda elaborada por Sexto Pompeyo para mejorar (y justificar) su posición como praefectus clasis et orae maritimae,

\footnotetext{
${ }^{23}$ Una cita de Dión Casio (Dio Cass. 48, 31, 5) indica que el pueblo de Roma identificaba la estatua de Neptuno con Sexto Pompeyo.

${ }^{24}$ Sobre esta emisión, vid: L. Amela Valverde, “La serie de Q. Nasidius (RRC 483)”, GN 148 (2003), 9-23; “De nuevo sobre la serie de Q. Nasidius (RRC 483)”, RN 161 (2005), 79-92
} 
aunque para J. H. Kroll la caracterización de Pompeyo con Poseidón es menos probable que se originase con Sexto Pompeyo en los años 40 que en el Oriente griego, donde la identificación del gobernante con una deidad era desde hacía mucho tiempo un accesorio de la vida política (Kroll 1993: 99 n. 201). Es decir, si bien se constata la identificación de Pompeyo con Neptuno a final de la década de los años 40, ésta debió ser anterior, aunque no nos ha quedado constancia.

Desde un punto de vista histórico, la ecuación se basa en los éxitos navales de Pompeyo sobre los piratas unos veinte años antes (en el 67 a.C.), y hubiera sido sorprendente si una asociación tan obvia hubiera pasado desapercibida durante la gira de Pompeyo por la cuenca del mar Egeo en el año 62 a.C., especialmente por los poetas que compitieron en Mitilene en glorificar las gestas de Pompeyo Magno (Plut. Pomp. 42, 2) (Kroll 1993: 99 n. 201). Atenas también glorificó a Pompeyo Magno (Plut. Pomp. 27, 5), ${ }^{25}$ lo que no es de extrañar pues éste dio a la ciudad un donativo de 50 talentos, que fue utilizado en la reconstrucción del puerto del Pireo (Plut. Pomp. 42, 11. IG II ${ }^{2}$ 1035, 1. 47) (Kroll 1993: 99 n. 201).

Pompeyo posiblemente hubiera podido iniciarse en los Misterios de Eleusis, ya que otros políticos romanos lo hacían, fuesen éstos de visita a Atenas o a tomar lecciones de filosofía (Kallet-Marx 1995: 203). Como los ritos de iniciación tenían lugar a finales de septiembre, es posible que Pompeyo pudiera haber coordinado su viaje hacia Italia con una parada en Atenas midiendo el tiempo para poder coincidir con el ritual (Kroll 1999: 93; Hoff 2005: 332). La confirmación de este hecho vendría gracias a la presente emisión, ya que si se considera que el anverso es una alusión a Pompeyo, las espigas de trigo del reverso indicarían precisamente que éste tomó parte de los Misterios de Eleusis (Hoff 2005: 332 n. 24). Pero no existe ninguna evidencia a favor de este hecho, es decir, se trata de teorías que se apoyan las unas en las otras.

El testimonio de esta amonedación, que pudo haber sido acuñada desde un punto de vista teórico durante la segunda visita de Pompeyo Magno a Atenas (62 a.C.) o en la década de los años 40s del siglo I a.C. (cuando Sexto Pompeyo reinaba en los mares) plantea un interesante debate: la relación de las emisiones provinciales con Roma. Evidentemente, las acuñaciones provinciales eran desde un punto de vista técnico "romanas", ya que formaban parte del Imperio Romano, aunque desde un punto de vista metrológico y figurativo se diferenciaba de ésta. No obstante, estaba al servicio de las autoridades romanas, que sin duda permitían su existencia.

\footnotetext{
${ }^{25}$ Sobre los honores concedidos a Pompeyo Magno por las comunidades griegas, vid: L. Amela Valverde, "Inscripciones honoríficas dedicadas a Pompeyo Magno", Faventia 23/1 (2001), 87-102; "Pompeyo y los honores cultuales. Algunos casos", en Actas del XXVII Congreso Internacional Girea-Arys IX. Historia Antigua. Jerarquías religiosas y control social en el mundo antiguo (Valladolid, 2004), 407-415.
} 
Ciertamente, sería muy interesante que la moneda Kroll 129 fuese testimonio de las actividades de Pompeyo Magno en Atenas, pero creemos que debemos esperar a nuevos descubrimientos para confirmar o descartar esta relación.

\section{LA CARTA DE CICERÓN}

La rivalidad entre políticos romanos también tuvo su plasmación en la ciudad ateniense. En una carta de M. Tulio Cicerón (cos. 63 a.C.) a T. Pomponio Ático fechada el 20 de febrero del año 50 a.C. se señala el malestar de Pompeyo sobre cómo se estaba utilizado el dinero que él había dado:

Et heus tu, tgenuat vos a Cesare per Herodem talenta Attica L extorsistis? In quo, ut audio, mágnum odium Pompei suscepistis; putat enim suos nummos vos comedisse, Caesarem in Nemore aedificando diligentiorem fore, haec ego ex P. Vedio, magno nebulone sed Pompei tamen familiari, audivit (Cic. Att. 6, 1, 25). ${ }^{26}$

La traducción sería: "Y oye tú, ¿le habéis arrancado "valerosamente" a César por medio de Herodes cincuenta talentos áticos? Con ello habéis provocado, según oigo, un gran odio de Pompeyo; piensa, en efecto, que lo que os habéis comido es su propio dinero, que César pondrá más celo en edificar en el bosque. Esto se lo he oído yo decir a Publio Vedio, un gran bribón, pero íntimo de Pompeyo».

César evidentemente correspondía a los cincuenta talentos de Pompeyo (concedidos doce años antes) con una suma igual suministrada a los atenienses (Rawson 1985: 45; Hoff 1989: 2, 2002: s.p.; Habicht 2000: 365). Cicerón no recuerda qué uso dieron éstos a los beneficios de César, pero es probable que los fondos fueran utilizados en construir el Ágora romana. Este dato lo conocemos gracias a una inscripción dedicada durante el arcontado de Nicias (ca. 10/9 a.C.) (Schonky y Welwei 2007: 166 y 177), grabada en el arquitrabe de la puerta de entrada de este mercado $\left(I G \mathrm{II}^{2} 3175=I G \mathrm{II}^{3} 4\right.$ 12), en el que se menciona la participación de César (Rawson 1985: 44-45; Hoff 1989a: 271, 1989b: 2, 1992: 231 n. 53, 2002 s.p., 2013 569; Habicht 2000: 365; Hasenhor y Müller 2002: 17; Borg 2011: 218; Toher 2014: 128; Dickenson 2015: 748; Heijnen 2018: 85; Mavrojannis 2019: 28). ${ }^{27}$ Como indica M. Hoff, es posible que esta construcción

26 Vid comentario a este pasaje en Shackleton Bailey 1965: 253-254.

${ }^{27}$ Como manifiesta M. Hoff, no tiene sentido la sugerencia de Oikonomides 1979: 101 n. 13, de considerar que César y Augusto no estuvieran directamente implicados en la construcción del Ágora romana, y que tal obra fuese acometida por atenienses acomodados. Igualmente, la planificación del Ágora romana no tiene por qué ser haber sido efectuada por Pompeyo, sino que más bien fue responsabilidad del monarca egipcio Ptolomeo IX Sóter II durante su último periodo de reinado (88-81 a.C.), como señala Mavrojannis 2019: 35 y 37.- Melfi 2010: 24, 2016: 156 señala que los donativos de Pompeyo y César son únicamente conocidos gracias a fuentes romanas, ya que ningún epígrafe ateniense señala de manera explícita la intervención de alguno de ellos en la restauración de la ciudad. 
esté relacionada con la llegada de Italici procedente de Delos, que había caído totalmente en declive. Sea como fuere, la construcción se paralizó debido al estallido de la Segunda Guerra Civil romana (Hoff 1992: 231 n. 53).

El Herodes mencionado por Cicerón es bien conocido. Se trata de Herodes de Maratón, arconte epónimo del año 60/59 a.C. (IG II ${ }^{2}$ 1716) (Schonky y Welwei 2007: 164 y 176), amigo del famoso orador, de quien parece escribió una historia de su consulado (Cic. Att. 2, 2, 2) y tutor de su hijo, que figura citado varias veces en su correspondencia (Cic. Att. 14, 16, 3; 14, 18, 4; 15, 27, 3; 16, 3, 2); este Herodes es el primer miembro conocido de una distinguida familia ateniense cuyas filas producirán en el siglo II d.C. al adinerado benefactor Herodes Ático (MacKendrick 1969: 64; Hoff 1989a: 271 n. 25, 1989b: 2, 2002: s.p., 2005: 333; Habicht 2000: 357 y 365; Morales 2015: 248-249; Heijnen 2018: 85). Y, precisamente, Herodes fue el superintendente a cargo de la construcción del Ágora romana, puesto en el que le sucedió su hijo $\left(I G \mathrm{II}^{2} 3175=I G \mathrm{II}^{3} 4\right.$ 12). ${ }^{28}$ Según M. Hoff, es posible que Herodes se hubiera entrevistado en el año 51 a.C. con César para obtener los fondos (Hoff 1989b: 2 y 7), a propuesta del propio ateniense. La participación de éste es evidente según la información de Cicerón.

Una información de Suetonio resulta particularmente útil. Este autor nos informa que César, en previsión del futuro, nec minore studio reges atque provincias per terrarum orbem adliciebat, (aliis captivorum milia dono offerens, aliis citra senatus populique auctoritatem, quo vellent et quotiens vellent,) superque Italiae Galliarumque et Hispaniarum, Asiae quoque et Graeciae potentissimas urbes praecipuis operibus exornans (Suet. Caes. 28, 1). Evidentemente, una de las ciudades afortunadas fue Atenas, como atestigua la carta de Cicerón (Habicht 2000: 365).

Pompeyo estaba realmente disgustado con la actitud de los atenienses, porque consideraba que sus fondos no estaban siendo utilizados de manera adecuada para sus intereses, y la información de Cicerón sugiere de manera implícita que el dinero de César tuvo un mejor uso (Hoff 2002: s.p., 2005: 334). Mientras que el Deigma sería utilizado por unos cuantos mercaderes y navieros, el Ágora romana, situada en el corazón de la ciudad, cerca de la Acrópolis, sería utilizada y disfrutada por todo el pueblo ateniense (Hoff 1989: 2, 2002: s.p., 2005: 334). El comentario de Cicerón señala algunos puntos de interés. En primer lugar, Pompeyo no podía tener, o al menos no había deseado ejercerla, la prerrogativa de especificar como utilizar sus fondos. Cicerón indica que la "extorsión" del donativo de César sólo podía haber ocurrido si César conocía en qué se iba a dedicar su dinero. Indudablemente, César era consciente del presente de Pompeyo y lo que ello implicaba. Y por supuesto, Herodes también lo sabía (Hoff 2002: s.p.). Para M. Hoff, hay poca duda que una de las mayores

\footnotetext{
${ }^{28}$ Eucles, el hijo de Herodes, arconte epónimo ca. el año 46/45 a.C., era en el momento de la dedicación estratega de los hoplitas, y así mismo tuvo éxito en solicitar fondos de Augusto para completar la construcción del Ágora (IG II2 3175).
} 
razones para el donativo de César era atraer partidarios de Pompeyo y ganar apoyo para sus aspiraciones políticas (Hoff 1989: 2 y 8, 2002: s.p.; Hasenhor y Müller 2002: 17; Melfi 2016: 156), aunque, a la vista de los resultados posteriores, tuvo poco éxito, pues en el año 48 a.C. Atenas se alineó con Pompeyo (Hoff 1989: 3, 2002: s.p.), vid infra. Como en el caso de Pompeyo, se ha dicho que César ya estaría buscando apoyo en las provincias en previsión de la posterior guerra civil (Rawson 1985: 46; Hoff 2002: s.p.). Más difícil sería conocer si la nobleza ateniense buscaba cambiar su lealtad política, es decir, de Pompeyo a César. También es posible que ambas donaciones, de igual cantidad, indicara un deseo ateniense de permanecer neutral entre los dos imperatores en competencia, ${ }^{29}$ aunque ello pudiera significar perder el patronato de Pompeyo (Hoff 2002: s.p.).

Más bien, en todo este asunto lo que se buscaba era aprovecharse de la competencia entre ambos líderes romanos. Que César otorgue la misma cantidad de dinero que Pompeyo es toda una declaración de intenciones (Dickenson 2015: 748). No hay que pensar que la política de César reflejada por Suetonio (o la de Pompeyo) fuese una excepción dentro de la nobleza romana. La construcción de edificios por parte de miembros de las clases dirigentes comienza a hacerse frecuente en la ciudad de Roma ya en el siglo II a.C., por no decir ya en el siglo I a.C. ${ }^{30}$

En el presente caso, una prueba de ello es el epígrafe (CIL I² $775=$ CIL III 547 = ILLRP 401 = ILS 4041) de Eleusis en el que se manifiesta que Ap. Claudio Pulcro (cos. 54 a.C.) construyó a sus expensas los pequeños propileos del santuario, monumento dedicado a las diosas eleusinas (Clinton 1989: 15041506). Curiosamente, Pulcro fue el predecesor de Cicerón en el gobierno de Cilicia (53-51 a.C.), y éste, en tal cargo, al enterarse de la obra patrocinada por Pulcro (en la misma época que César hace su donativo) (Habicht 2000: 365-366), piensa en hacer lo mismo, pero en la Academia (Cic. Att. 6, 1, 26). Pero, seis meses más tarde, cuando le ha dado varias vueltas al asunto, Cicerón al parecer considera que la obra esta fuera de lugar (Cic. Att. 6, 6, 2). La competición entre ambos personajes (Morales 2015: 231) nos recuerda la existente entre Pompeyo y César, pero a menor escala.

$\mathrm{Cl}$. Eilers cree que este tipo de donativos fueron de carácter excepcional (Eilers 2002: 98 n. 67). Pero a nuestro entender éstos debieron ser más comunes

29 Graindor 1930: 6-7; Day 1942: 130-131 n. 60; Geagan 1979: 377; Shear 1981: 358-359 consideraron que el donativo de César fue otorgado en el año 47 a.C., al desconocer el testimonio de Cicerón.

30 Por ejemplo, para Pompeyo, vid: D. MacKendrick, "Nabobs as builders, Sulla, Pompey, Caesar", CJ 55 (1960), 241-256. E. Frézouls, "La construction du «theatrum lapideum» et son contexte politique", en Théâtre et spectacle dans l'Antiquité. Actes du Colloque de Strasbourg (Leiden, 1981), 193-214. G. Sauron, “Le complexe pompéien du Champ de Mars: nouveauté urbanistique à finalité idéologique", en L'urbs. Espace urbain et histoire (Ier s. avant J.-C. - IIIe siècle après J.-C.) (Rome, 1987), 457-473. F. Coarelli, “Le théâtre de Pompée”, DHA 23/2 (1997), 105-124. 
(aunque a una escala mucho menor). La actitud de César que describe Suetonio no debió ser única, sino responder a una realidad existente, que, por desgracia, la documentación actualmente existente no registra en amplitud. Sea como fuere, los donativos tanto de Pompeyo como de César muestran la intervención romana en las principales comunidades del mundo mediterráneo (Galli 2013: 39), y confirma el especial papel de Atenas en la geografía política de la conquista romana, como venerada capital cultural, sede del pensamiento democrático y filosófico (Camp 2001: 183; Melfi 2016: 156-157). Otras actuaciones arquitectónicas fueron efectuadas en este tiempo en Atenas. Por ejemplo, se restauró en el Asklepieion, como recoge un decreto del año 52/51 a.C. (IG II ${ }^{2}$ 1046), el Odeón entre los años 63 y 51 a.C. (Vitr. 5, 9, 1. IG II² 3426) ) $^{31}$ así como el Teatro de Dioniso (IG II ${ }^{2}$ 3427) (Day 1942: 129; Hoff 1997: 41). ${ }^{32}$ También se reconstruyeron los lienzos de la muralla derribados por Sila pues, sometida la ciudad a asedio en el año 48 a.C., resistió a éste (Dio Cass. 42, 14, 1), como muestra la arqueología (Pounder 1983: 256; Borg 2011: 218; Theocharaki 2011: 129; Morales 2015: 249; Parigi 2016: 390): «Caleno había sido enviado por César a Grecia antes de la batalla [de Pharsalus] y, entre otros lugares había conquistado el Pireo porque se encontraba desguarnecido; pero no pudo conquistar Atenas antes de la derrota de Pompeyo a pesar de haber devastado la mayor parte de la región». La reparación de las murallas debió ser una prioridad (Borg 2011: 218).

\section{LA SEGUNDA GUERRA CIVIL ROMANA}

El enfrentamiento entre el Senado y César abocará a la Segunda Guerra Civil (49-45 a.C.). Pompeyo, comandante de las fuerzas republicanas, se verá obligado a dirigirse a Grecia con objeto de preparar un segundo frente. Para ello, Pompeyo pidió contribuciones a las comunidades orientales en forma de tropas, barcos y dinero para ayudar a su esfuerzo.

Para Chr. Habicht, esto fue logrado gracias en parte a sus relaciones personales, aunque las comunidades se vieron de hecho obligadas a actuar de esta manera (Habicht 2000: 384). Como es lógico, Atenas militó en el bando pompeyano pero las fuentes presentan un panorama confuso respecto a su determinación en el conflicto (Hoff 2002: s.p.).

Parece que Atenas sondeó por un instante proclamar su neutralidad en el conflicto (Habicht 2000: 384; Hoff 2002: s.p.). No ha de extrañar. Sin duda los atenienses recordaban los desastrosos resultados de su participación en la

31 Vitruvio menciona que el rey Ariobarzanes II Filopátor (63/62-52/51 a.C.,) se encargó de pagar la reconstrucción del Odeón, como confirma la inscripción mencionada.- Morales 2015: 81 señala que la restauración del Odeón no tiene nada que ver con el donativo efectuado por Pompeyo, debido a que no figura su nombre (o marcas de borrado en su caso) en los epígrafes que mencionan este hecho.

32 Thompson 1941: 223 lanza la hipótesis de que parte de los fondos donados por Pompeyo se dedicaron a este impresionante monumento, el mayor teatro de la antigua Grecia. 
Primera Guerra Mitridática y es comprensible que buscaran una excusa para no intervenir en un conflicto (Hoff 2002: s.p.). Apiano (BCiv. 2, 70). nos indica que:

También participaban en la campaña (del lado de Pompeyo) atenienses, aunque éstos habían hecho una proclama pública de que ellos no cometerían ningún acto de violencia contra el ejército de uno u otro bando, pues estaban consagrados a las Tesmoforias, pero ansiaban, no obstante, tomar parte en la gloria de la guerra, porque se iba a luchar por el liderazgo de los romanos.

Las Tesmoforias era un festival en honor a Deméter y Kore, en la que participaban exclusivamente mujeres, que en Atenas se celebraba del 7 al 11 del mes pyanopsion, correspondiente a octubre-noviembre. Como la batalla decisiva de la campaña aconteció en Pharsalus el día 9 de agosto del año 48 a.C., forzosamente la noticia debería referirse al año 49 a.C. A pesar de la cita de Apiano, para E. J. Owens los atenienses deseaban determinar ellos mismos su destino. Eso sí, ambos bandos tendrían cuidado para evitar sufrimientos a esta antigua y venerable ciudad (Owens 1976: 720), lo que no es precisamente correcto, pues el legado cesariano Q. Fufio Caleno (cos. 47 a.C.) la sometió a sitio, y la rendición de Atenas seguidamente a la batalla de Pharsalus pudo librarla de un destino semejante a Megara (Mégara, Ática), duramente castigada (Dio Cass. 42, 14, 3-4). Algunos meses antes de la batalla decisiva, P. Cornelio Dolabela (cos. suff. 44 a.C.), legado de César y yerno de Cicerón, escribió a este último una carta en su campamento frente a Dyrrachium, quizás a sugerencia de César (Shackleton Bailey 1977: 498; Wistrand 1979: 165), en la que le exhortaba a que se retirara del campamento de Pompeyo y solicitara asilo "en Atenas o en otra ciudad tranquila": petere ... ut tu te vel Athenas vel in in quamvis quietam civitatem (Cic. Fam. 9, 9, 3) 33 . Pero, Atenas estaba ya comprometida del lado de Pompeyo (Habicht 2000: 486 n. 62). Se supone que Dolabela no habría mencionado la ciudad de Atenas a Cicerón si esta ciudad estuviera vinculada al bando de Pompeyo (Hoff 2002: s.p.), pero hay que tener en cuenta que el asilo de Cicerón se produciría si Pompeyo se retiraba de Grecia. En el supuesto caso que Atenas no quisiera participar en el conflicto, su decisión fue efímera. Quizás los atenienses ejercieran un cálculo político y esperaran todo lo posible hasta decantarse por el bando que saliera vencedor. En este caso, los amplios recursos obtenidos por Pompeyo, su superioridad numérica sobre César ${ }^{34}$ pudieron decantar la balanza (Hoff 2002: s.p.). El resultado favorable a Pompeyo obtenido en la batalla de Dyrrachium puede haber sido definitivo pero, en verdad, la participación ateniense ya se habría decantado anteriormente cuando los

33 Wistrand 1979: 165 señala que la carta fue escrita cuando los cesarianos creían tener la victoria en sus manos.

${ }^{34}$ A partir de la información de Plutarco (Plut. Caes. 42, 4) las tropas de infantería de Pompeyo superaban en número a las de César por más de dos a uno, lo que literalmente señala Apiano (App. BCiv. 2, 70). 
republicanos formaron su flota. Difícilmente Atenas pudo ignorar el requerimiento efectuado a tal efecto. P. MacKendrick considera que Atenas se unió a Pompeyo al recordar que había barrido a la piratería del mar Egeo (MacKendrick 1969: 65), mientras que M. L. Benavides piensa que fue por su anterior donativo de cincuenta talentos (Benavides 2019: 22). Más bien, la presencia del ejército de Pompeyo en Macedonia fue lo que decidió a Atenas (y al resto de comunidades) a apoyar a su bando. Su derrota significó inmediatamente un cambio en la orientación partidista, a excepción de ciertas poblaciones, como Mégara. Los reyes y dinastas de Oriente fueron fieles a Pompeyo entretanto éste fue representante de Roma, pero sólo mientras su aureola de poder y de invencibilidad se mantuvo; cuando ésta desapareció, simplemente, le abandonaron. No en vano César, después de la guerra de Alejandría, al dirigirse contra Farnaces II, rey del Bósforo (63-47 a.C.), que había invadido el Ponto, recogió de manera apresurada el homenaje de toda la pléyade de dinastas existentes en Siria, quienes fueron recepti in fidem, es decir, admitidos en su clientela, a cambio de lo cual César les prometió su amicitia. Este es un punto significativo (casi fundamental) para comprender la fría acogida que obtuvo Pompeyo a su llegada a Oriente en el año 49 a.C., cuando había estallado el conflicto entre César y el Senado. Esto puede fácilmente comprobarse por los pobres destacamentos militares que los dinastas pusieron a su disposición. Una prueba evidente es que Pompeyo fue asesinado a manos de uno de sus supuestos monarcas clientes, Ptolomeo XIII de Egipto (51-47 a.C.) (Amela 2003b: 170). ${ }^{35}$

En cuanto a los efectivos proporcionados por Atenas, un pequeño número de barcos atenienses, no más de tres, cifra quizás excesivamente baja (Habicht 2000: 384), según Lucano (Luc. 3, 181-183), ${ }^{36}$ vino a reforzar la flota de Pompeyo, ya muy superior a la de su adversario, a quien se le intentaba impedir que cruzara el mar Jónico.

Asimismo César menciona a Atenas entre los estados que contribuyeron a la flota de Pompeyo, lo que da a pensar a Chr. Habicht que no fue tan pequeño el número de barcos de guerra que aportó (Habicht 2000: 385). Por su parte, M. Hoff considera que el bajo número de embarcaciones en la leva

${ }^{35}$ No es muy difícil seguir esta conducta: el inventario de contingentes militares que César hace de las tropas no romanas de Pompeyo, que se asemeja, para su propia exaltación contra los bárbaros, al catálogo que realizó Heródoto sobre el ejército persa, es largo en nombres pero parco en cifras. La movilización de los provinciales en este conflicto no fue muy importante, y quizás, en parte, impuesta. Pompeyo, de lo único que podía presumir, era de una imponente flota. La respuesta puede estar en que entre los habitantes de Oriente estaba todavía vivo el recuerdo de los conflictos entre los sucesores de Alejandro Magno. Para ellos, la guerra civil no era más que un conflicto interno entre Romanos, en el cual no deseaban participar.

${ }^{36}$ Exhausit totus quamvis dilectus Athenas, / exiguae Phoebea tenent navalia puppes / tresque petunt verum credi Salamina carinae. Livio, posiblemente la fuente de Lucano, escribió: nam Atenienses de tanta marítima gloria vix duas naves effecere (Liv. Per. 109 fr. 36), según Comm. Bern. 
ateniense probable refleja el estado pobre de la preparación naval en los años siguientes a Sila y también el deseo romano de limitar el equipo militar (Hoff 2002: s.p.). Quizás la mención de Atenas por César al hablar de las fuerzas navales de Pompeyo (Caes. BCiv. 3, 3, 1) fuera más simbólica que otra cosa. De hecho, en una carta de Cicerón del 17 de marzo del año 49 a.C. se lista los lugares de procedencia de la flota que estaba reuniendo Pompeyo (Cic. Att. 9, 9, 2), y Atenas no aparece en ella. ${ }^{37}$

Sea como fuere, la contribución de Atenas en el número de soldados de infantería en el ejército de Pompeyo parece haber sido más importante, pues Lucano, exagerando en sentido inverso que con la flota, señala que su reclutamiento dejó a Atenas vacía de lo mejor de sus fuerzas movilizables (Luc. 3, 181). Al parecer, Pompeyo tenía en gran consideración este contingente (Habicht 2000: 385), pues en la batalla de Pharsalus situó esta fuerza al lado inmediato de las legiones itálicas (App. BCiv. 2, 75). Curiosamente, César no menciona fuerza ateniense alguna a la hora de listar las fuerzas a disposición de Pompeyo (Caes. BCiv., 3, 4) (Hoff 1989a: 271 n. 24).

J. Day considera incierto si soldados atenienses participaron en las fuerzas de Pompeyo, al no aparecer éstos citados en César (Caes. BCiv. 3, 4, 2-3) (Day 1942: 130) ni si tuvieron que aportar dinero: César recuerda que las ciudades libres de Achaea (es decir, Grecia, al menos en este pasaje) (Larsen 1938: 431 n. 18) fueron obligadas a dar dinero a Pompeyo (Caes. BCiv. 3, 3, 2). La no mención de efectivos auxiliares por parte de César no ha de extrañar, pues los autores romanos generalmente no las describen, por considerarlas extranjeras y de escasa importancia en cuanto a su contribución al resultado de la contienda (Amela 2003b: 170).

En un momento anterior a la batalla decisiva celebrada en la llanura de Pharsalus, César envió a su legado Caleno (cos. 47 a.C.) con quince cohortes en dirección a la Grecia meridional (Plut. Caes. 43, 1). El objetivo de esta maniobra era ocupar el Peloponeso (Habicht 2000: 385) ${ }^{38}$ (Caes. BCiv. 3, 56, 1), pero el Istmo fue fortificado para impedírselo (Caes. BCiv. 3, 56, 3).

En su camino Caleno obtuvo la sumisión voluntaria de Delfos, Tebas y Orcómeno, aunque tomó otras ciudades por la fuerza (Caes. BCiv. 3, 56, 4). Así mismo, el legado cesariano envió embajadas a distintas comunidades de Grecia para atraérselas a su bando (Caes. BCiv. 3, 56, 4). Quizás entre éstas estuviera Atenas (Oikonomides 1979: 100). Es posible que ante la imposibilidad de cruzar

\footnotetext{
37 Holmes 1923: 113, a pesar de las divergencias entre César y Cicerón en la procedencia de las naves, sólo menciona la lista del primero de ambos autores. Por su parte, Rossi 2000: 248 únicamente menciona el repertorio dado por César. Zollschan 2007: 32-33; Augier 2018: 73 n. 8 mencionan la composición de la flota de Pompeyo a partir de ambas fuentes.

38 Aquí Achaea es la península peloponésica, como indica Larsen 1938: 431 n. 18.
} 
el istmo, debido a la hostilidad de la ciudad de Mégara, ${ }^{39}$ Caleno decidiera atacar el Ática. Además, es posible que el ataque contra El Pireo y Mégara ${ }^{40}$ estuviera determinado por el deseo de César de privar a Pompeyo de buenos puertos para su flota así como de astilleros (Oikonomides 1979: 101). El propio César recuerda que Pompeyo dio orden de construir naves para su armada (Caes. BCiv. 3, 3, 2). Entre sus objetivos, Caleno ocupó El Pireo, que se encontraba desprovisto de defensas ${ }^{41}$. Pero no pudo conquistar Atenas (demostración de que estaba del bando de Pompeyo) antes de Pharsalus, y tuvo que contestarse con devastar los distritos rurales (Dio Cass. 42, 14, 1). ${ }^{42}$ Se ha deducido de la anterior carta de Dolabela que los atenienses probablemente no soportarían el sitio de Caleno por mucho tiempo (quizás sólo unas pocas semanas) antes de la batalla de Pharsalus (Hoff 2002: s.p.). Pero, evidentemente, el resultado de esta última determinó el curso de los acontecimientos. Uno de los propósitos de Caleno podría haber sido contener a un contingente pompeyano posiblemente establecido en Atenas. Un epitafio en latín (CIL I 791 = CIL III 6541 = CIL III 12280 = ILLRP 502 = ILS 2249) procedente de la ciudad recuerda al centurión N. Granonio, de la segunda legión pompeyana, que probablemente murió en estos combates (Rawson 1985: 46; Habicht 1997: 9, 2000: 385 ; Hoff 2002: s.p., 2005: 336; Parigi 2013: 447). ${ }^{43}$

Inmediatamente después de la victoria de César, Atenas hace adhesión al vencedor. César «sin guardarles rencor, los dejó impunes. Tan solo les dijo que, aunque habían cometido muchos errores, habían sido salvados por sus muertos. Esta expresión ponía de manifiesto que los había perdonado por la gloria y la excelencia de sus antepasados» (Dio Cass. 42, 14, 2). La misma opinión que anteriormente había dado Sila (Plut. Sull. 14, 9). La conservación de una dedicación en Atenas de un epígrafe a César (SEG XIV 121) muestra esta política, sin duda, una pálida muestra de los honores que se le dedicaron.

39 Vid: L. Amela Valverde, “La campaña de Q. Fufio Caleno en Grecia en el año 48 a.C. y la ciudad de Mégara. Las consecuencias de la guerra", Athenaeum 96 (2008), 279-291

40 Ante la inminencia de la batalla, César reunió a sus soldados y les preguntó si querían ir solos al combate o esperar los refuerzos de Q. Cornificio (pr. 45 a.C.) y de las fuerzas dirigidas por Caleno, que se encontraban en los alrededores de Mégara y Atenas (Plut. Caes. 43, 1).

${ }^{41}$ Caleno recibió homenajes en Oropus (IG VII 380) y Olympia (I.Olympia 330). Oikonomides 1979: 99-100 considera que gracias a la intervención de este personaje la población beocia de Oropo pudo librarse del yugo ateniense durante el periodo de los años 48-42 a.C. En realidad, como indica Habicht 2000: 488 n. 101, Oropo no se incorporará al territorio ateniense hasta época de Augusto.

42 Los edificios de Atenas sufrieron poco, si alguno, daño físico como resultado del sitio de Caleno, aunque no en el caso de El Pireo (Cic. Fam. 4, 5, 4).

${ }^{43}$ Sobre este epígrafe, vid: L. Amela Valverde, “Un centurión romano en Athenae (CIL I² 791): La numeración de las legiones tardorrepublicanas", RÉMA 5 (2008-2012), 99-108. A. Kozlenko, "Where did Numerius Granonius serve? Military career of the Roman centurion in the Civil War Epoch", Parabellum novum 5 (2016), 48-53 [en ruso]. 
Apiano es mucho más preciso: «Este último (César) permaneció en Pharsalus dos días después de su victoria, ofreciendo sacrificios y concediendo un respiro del combate al ejército; en este tiempo, dejó marchar en libertad a los tesalios, que habían combatido como aliados suyos, y concedió el perdón, previa solicitud, a los atenienses, a quienes dijo: “¿Cuántas veces os salvará de la autodestrucción la gloria de vuestros antepasados?"» (App. BCiv. 2, 88). El prestigio de Atenas, debido a no ser sólo el centro del helenismo, sino incluso la cuna de la civilización (Alcalde 2013: 41), es lo que permite a la ciudad no sólo su subsistencia sino su mantenimiento como centro cultural durante el Imperio Romano a pesar de haber perdido su peso en el campo político. Si bien ciertamente E. Gruen señaló que los romanos distinguían entre admiración privada y práctica pública) Gruen 1984: 267), en el caso de Atenas parece claro que tal admiración afectaba a las decisiones políticas (Kralli 2016: 177).

Ciertamente, los atenienses no perdieron el tiempo. Esta prontitud es señal, como bien indica Chr. Habicht, de que una delegación ateniense se encontraría en las proximidades al campo de operaciones, lista para, después de la batalla, presentar su homenaje al vencedor y, según el caso, recordar los servicios prestados o pedir como suplicante el perdón (Habicht 2000: 385). Podía haber acontecido algo parecido a Massalia. Esta ciudad intentó mantener su neutralidad en la guerra civil entre sus patrones, pero, forzada por las circunstancias, eligió paes iustiorem habeat causam (Caes. BCiv. 1, 35, 3), es decir, la más conforme a los intereses ideológicos de la oligarquía rectora de la ciudad, es decir, Pompeyo. ${ }^{44}$ Su elección no fue tan pura como pareciera en un principio, $\mathrm{y}$ en realidad con su decisión buscaba recuperar su antiguo papel en el Mediterráneo occidental y en el comercio galo, en la que había sido substituida por los negotiatores itálicos. En realidad, como se puede observar a través del Bellum Gallicum de César, en la Galia Transalpina afloraba una sociedad romano-indígena (dominada por una poderosa aristocracia nativa leal y guerrera), que gradualmente oscurecerá a Massalia, como queda reflejado en que ninguno de sus habitantes aparezca citado en la obra cesariana, ni tan siquiera la propia ciudad.

Massalia sucumbió a manos de los cesarianos en el año 49 a.C. Ello le costó la pérdida de sus armas, sus máquinas de guerra, sus barcos, su tesoro (Caes. BCiv. 2, 22, 5), aunque la ciudad no fue destruida gracias a su nombre y antigüedad (Caes. BCiv. 2, 22, 6), lo mismo que Atenas. ${ }^{45}$ La mayor parte del territorio massaliota fue incorporado al de la nueva colonia de Arelate (Arlés, dept. Bocas del Ródano). El propio Estrabón señala la decadencia de Massalia por haberse adherido al bando perdedor (Str. 4, 1, 5). Atenas salió mucho mejor

\footnotetext{
${ }^{44}$ De hecho, en el mismo año 49 a.C. Pompeyo despidió a una embajada massaliota en Roma recordándoles que no olvidasen sus beneficios anteriores (Caes. BCiv. 1, 34, 3).

${ }^{45}$ Los autores clásicos ya señalaron que César dejó a la ciudad su vida y su libertad, pero se quedó con todo el resto (Dio Cass. 41, 25, 3. Oros. 6, 15, 7).
} 
parada que la antigua colonia focea, pero no aprendió la lección, y en los posteriores enfrentamientos volverá a alinearse con el bando perdedor, sea con M. Junio Bruto (pr. 44 a.C.) o con M. Antonio (cos. I 44 a.C.). Posiblemente, por las mismas razones por las que se alineó con Pompeyo: la presencia directa o cercana de las fuerzas militares del caudillo de turno, aunque siempre acabó bien librada.

El ejemplo de Atenas es clarificador de lo que podía realmente significar la clientela provincial: los reyes y dinastas de Oriente siguieron a Pompeyo mientras éste mantuvo su aureola de poder y de invicto; cuando ésta desapareció, simplemente le abandonaron. No en vano César, después de la guerra de Alejandría, al dirigirse contra Farnaces II, recogió de manera apresurada el homenaje de toda la pléyade de dinastas existentes en Siria, quienes fueron recepti in fidem, es decir, admitidos en su clientela, a cambio de lo cual César les prometió su amicitia (BAlex. 65, 4) (Amela, 2003a: 74).

\section{BIBLIOGRAFÍA}

Aguilar, R. M. y Pérez Vilatela, L. (2004), Plutarco. Vidas de Sertorio y Pompeyo. Edición de ..., Madrid, Akal.

Alcalde MARTín, C. (2013), "Athenae Captae, Athenae Receptae (Plutarco, Atenas y Roma)", en Figure d'Atene nelle opere di Plutarco, Casanova, A. (ed.), Firenze, Firenmze University Press, 31-49.

Amela Valverde, L. (2001), "Inscripciones honoríficas dedicadas a Pompeyo Magno", Faventia 23/1, 87-102.

Amela Valverde, L. (2003a), Las clientelas de Cneo Pompeyo Magno en Hispania, Barcelona, Universidad de Barcelona.

Amela Valverde, L. (2003b), Cneo Pompeyo Magno, el defensor de la República romana, Madrid, Signifer Libros.

Amela VALVerde, L. (2004), "Pompeyo y los honores cultuales. Algunos casos", en Actas del XXVII Congreso Internacional Girea-Arys IX. Historia Antigua. Jerarquías religiosas y control social en el mundo antiguo, Hernández Guerra, L. y Alvar Ezquerra, J. (eds.), Valladolid, Universidad de Valladolid, 407-415.

Amela Valverde, L. (2005), “Pompeyo Magno y Atenas”, Polis 17, 7-30.

Amela VAlverde, L. (2013), “Pompeyo Magno y Atenas. Sobre la emisión Kroll 129”, en Varia nummorum II, Barcelona, Asociación Numismática Española, 193-197.

AugIER, B. (2018), “La politique est plus dangereuse que la guerre: Pompée et la flotte de l'Adriatique (49-48 av. J.-C.)", en Arcana Imperii. Mélanges d'histoire économique sociale et politique offerts au Professeur Yves Roman. Volume second, Chillet, Cl.,; Courrier, C. y Passat, L. (eds.), Paris, Société des amis de Jacob Spon, 71-113.

Benavides, M. L. (2019), The Romanization of Attic Ritual Space in the Age of Augustus, Diss. Tucson, The University of Arizona.

BORG, B. E. (2011), "Who Cared about Greek Identity? Athens in the First Century BC", en The Struggle for Identity. Greeks and their Past on the First Century BCE, Schmitz, Th. A. y Wiater, N. (eds), Stuttgart, Steiner Franz Verlag, 213-234. 
BREnNAN, T. C. (2000), The Praetorship in the Roman Republic, Oxford, Oxford University Press.

BRunT, P. A. (1988), "Clientela", en The Fall of the Roman Republic and Related Essays (Oxford, Oxford University Press, 382-442.

CAMP, J. M. (2001), The Archaeology of Athens, New Haven/London, Yale University Press..

CARCOPINO, J. (19685), Jules César, Paris, PUF.

ClASSEN, C. J. (1963), “Gottmenschentum in der römischen Republik”, Gymnasium 70, 312-338.

CLINTON, K. (1989), “The Eleusinian Mysteries: Roman Initiates and Benefactors, Second Century B.C. to A.D. 267", ANRW II 18. 2, 1499-1539.

COLLINS, H. P: (1953), “Decline and Fall of Pompey the Great”, GER 22, 98-106.

CRAWFORD, M. H. (1982), La república romana, Madrid, Taurus.

DAY, J. (1942), An Economic History of Athens under Roman Domination, New York, Columbia University Press.

DíAZ FERnÁNDEZ, A. (2015), Provincia et Imperivm. El mando provincial en la República romana (227-44 a.C.), Sevilla, Editorial Universidad de Sevilla.

DicKenson, CHR. P. (2015), "Pausanias and the 'Archaic Agora' at Athens", Hesperia 84, 723-770.

DUMONT, A. (1871), "Mémoire sur les jeunes gens étrangers admis dans le collège des éphebes à Athenes", CRAI 15, 4-25.

EDWARDS, K. L. (1997). Captive Gods: Romans and Athenian Religion from 229 B.C. to the Age of Augustus, Diss. Charlottesville, University of Virigina.

EILERS, C. (2002), Roman Patrons of Greek Cities, Oxford, Oxford University Press.

FERRARY, J.-L. (1997), “De l'évergétisme hellénistique à l'évergétisme romain”, en Actes du Xe Congrès International d'épigraphie grecque et latine (Paris, Éditions de la Sorbonne, 199-225.

FlaceliÈre, R. y CHAmbry, E. (1973), Plutarque. Vies. Tome VIII. Sertorius-Eumène Agésilas-Pompée. Texte établi et traduit par..., Paris, Les Belles Lettres

GAlLI, M. (2013), "Ritual Dynamics in the Greek Sanctuaries under the Romans", en Roman Power and Greek Sanctuaries. Forms of Interactions and Communication, Galli, M. (ed.), Athens, Scuola Archeologica di Atene/Sapienzà Università di Roma, 9-43.

GEAGAN, D. J. (1979), “Roman Athens: Some Aspects of Life and Culture, I: 86 BC-AD 267", ANRW II 7. 1, 371-437.

Gelzer, M. (1969), The Roman Nobility, Oxford, Blackwell Publishers.

GRAINDOR, P. (1930), Un milliardaire antique, Hérode Atticus et sa famille, Le Caire, Hachette.

Greenhalgh, P. (1980), Pompey, the roman Alexander, London, Weidenfeld and Nocolson.

Grigoropoulos, D. (2005), After Sulla. A Study in the Settlement and Material Culture of the Piraeus Peninsula in the Roman and Late Roman Period. 2 vols., Diss. Durham, University of Durham.

Grigoropoulos, D. (2016), "The Piraeus from 86 BC to Late Antiquity: Continuity and Change in the Landscape, Function and Economy of the Port of Roman Athens", ABSA 111, 239-268. 
Groeber, P. (1909), “Eine Atheinische Ehreninschrift des Sex. Pompeius, des grossvaters des Triumvirs", $M D A I(A)$ 34, 403-406.

GRuEN, E. (1984), The Hellenistic World and the Coming of Rome, Berkeley, University of California Press.

HABICHT, CHR. (1997), "Roman citizens in Athens (228-31 B.C.)", en The Romanization of Athens. Proceedings of an International Conference held at Lincoln, Nebraska (April 1996), Hoff, M. C. y Rotroff, D. I. (eds.), Oxford, Oxbow Books, 9-17.

HABICHT, CHR. (2000), Athènes hellénistique. Histoire de la cité d'Alexandre le Grand à Marc Antoine, Paris, Les Belles Lettres.

HASENHOR, CL. Y MÜLLER, CHR. (2002), “Gentilices et circulation des italiens: quelques réflexions méthodologiques", en Les Italiens dans le monde Grec. IIe siècle av. J.-C.Ier siècle ap. J.-C. Circulation, activités, integration, Müller, C. (ed.), Paris, École française d'Athènes, 11-20.

Heftner, H. (1995), Plutarch und der Aufstieg des Pompeius. Ein historischer Kommentar zu Plutarchs Pompeiusvita. Teil I: Kap. 1-45, Frankfurt am Main, Peter Lang.

Hoff, M. C. (1989a), "Civil Disobedience and Unrest in Augustan Athens”, Hesperia 58, 267-276.

Hoff, M. C. (1989b), "The Early History of the Roman Agora at Athens”, en The Greek Renaissance in the Roman Empire. Papers from the Tenth British Museum Classical Colloquium, Walker, S. y Cameron, A. (eds.), London, University of London, 1-8.

HOFF, M. C. (1992), "Augustus, Apollo, and Athens", MH 49, 223-232.

HofF, M. C. (1997), “Laceratae Athenae: Sulla's siege of Athens in 87/6 B.C. and its aftermath", en The Romanization of Athens. Proceedings of an International Conference held at Lincoln, Nebraska (April 1996), Hoff, M. C. y Rotroff, D. I. (eds.), Oxford, Oxbow Books, 33-51.

Hoff, M. C. (2002), "Athens and Pompey: A Political Relationship", en Ancient Journeys: A Festschrift in Honor of Eugene Numa Lane, Columbia, Columbia University Press, s.p.

Hoff, M. C. (2005), "Athens honors Pompey the Great", en Statesman in Plutarch's Works. Proceedings of the Sixth International Conference of the International Plutarch Society. Volume II. The Statesman in Plutarch's Greek and Roman Lives, De Blois, L. et alii (eds.), Leiden/Boston, Brill, 327-336.

Hoff, M. C. (2013), "Greece and the Roman Republic: Athens and Corinth from the Late Third Century to the Augustan Era", en Evans, J. D. (ed.), A Companion to the Archaeology of the Roman Republic (Malden/Oxford/Chichester, WileyBlackwell, 559-577.

Holmes, T. R. (1923), The Roman Republic and the Founder of the Empire, Volume III (50-44 B.C.), Oxford, Clarendon Press.

Hoover, O. D. (2014), The Handbook of Greek Coinage Series. Volume 4. Handbook of Coins of Northern and Central Greece. Achaia Phthiotis, Ainis, Magnesia, Malis, Oita, Perrhabia, Thessaly, Akarnania, Aitolia, Lokris, Phokis, Boiotia, Euboia, Attica, Megaris, and Corinthia. Sixth to First Centuries BC, Lancaster/London, Classical Numismatic Group.

Kallet-MarX, R. M. (1995), Hegemony to Empire: The Development of the Roman Imperialism in the East from 148 to 62 BC, Berkeley, University of California Press.

KLeINeR, F. S. (1975), Greek and Roman Coins of Athenian Agora, Princeton, American School of Classical Studies at Athenss. 
KOPIJ, K. (2017), Auctoritas et dignitas: studium prestiżu i propagandy w okresie późnej Republiki Rzymskiej na przykładzie rodu Pompejuszy (gens Pompeia Magna) w świetle źródeł archeologicznych i pisanych, Kraków, [Kamil Kopij].

KRALLI, O. (2016), "Attitudes of Hellenistic Athens: to sneer or to revere?", en 'The Eyesore of Aigina': Anti-Athenian Attitudes across the Greek, Hellenistic and Roman Worlds, Powell, A. y Meidani, K. (eds.), Swansea, Classical Press if Wales, 163186.

Kroll, J. (1999), The Athenian Agora. XXVI. The Greek Coins, Princeton, The American School of Classical Studies at Athens.

KRUMEICH, R. (2014), “Ehrung Roms und Stolz auf die Polis. Zur Repräsentation römischer Magistrate auf der Akropolis von Athen", en Polis und Porträt. Standbilder als Medien der öffentlichen Repräsentation im hellenistischen Osten, Griesbach, J. (ed.), Wiesbaden, Dr. Ludwig Reichert Verlag, 141-153.

LARSEN, J. A. O. (1938), "Roman Greece”, en Economic Survey of Ancient Rome. Volume IV. Africa, Syria, Greece, Asia Minor, Frank, T. (ed.), Baltimore, John Hopkins Press, 259-498.

LEACH, J. (1978), Pompey the Great, London, Routledge.

KALlet-MARX, K. (1995), Hegemony to Empire. The Development of the Roman Imperium in the East from 148 to 62 B.C., Berkeley, University of California Press.

MaCKendricK, P. (1969), The Athenian Aristocracy 399 to 31 B.C., Cambridge, Harvard University Press.

MAVROJANNIS, TH. (2019), "The Royal Donations of Ptolemy IX Soter II Lathyros in Athens: the "Gymnasium of Ptolemy» and the Horologium of Andronicus Cyrrhestes", Ostraka 28, forthcoming.

MeLFI, M. (2010), "Uestigiis reuolsorum donorum, tum donis dives erat (Livy XLV, 28): the Early Roman Presence in the Asklepeia of Greece", Bollettino di Archeologia on line. Volume special, 20-27.

MelfI, M. (2016), "Religion and Communication in the Sanctuaries of Early-Roman Greece: Epidauros and Athens", en Roman Power and Greek Sanctuaries. Forms of Interactions and Communication, Galli, M. (ed.), Athens, Scuola Archeologica di Atene/Sapienzà Università di Roma, 143-158.

Morales, F. A. (2015), Atenas e o Mediterrâneo romano. Espaço, evergetismo e integraçâo, Diss. Sâo Paulo, Universidade de Sâo Paulo

Morales, F. A. (2016), “The Restoration of Perikles' Odeion at Athens in the First Century BC: New and Ancient Barbarians", Revista Heródoto 1, 73-90.

MÜLLER, CHR. (2017), “"Les Athéniens, les Romains et les autres Grecs»: groupes et phénomènes de recomposition sociale dans la «colonie» athénienne de Délos après 167 av. J.-C.", en Social Dynamics under Roman Rule. Mobility and Status Change in the Provinces of Achaia and Macedonia, Rizakis, A. D.; Camia, F. y Zoumbaki, S. (eds.), Athens, National Hellenic Research Foundation, 85-117.

Nicols, J. (1980), “Tabulae patronatus: A Study of the Agreement between Patron and Client-Community", ANRW II 13, 535-561.

OIKONOMIDES, Al. N. (1979), "Defeated Athens, The Land of Oropos, Caesar and Augustus. Notes on the sources for the history of the years 49-27 B.C.", AncW 2, 97-103.

Oliver, J. H. (1972), "On the Hellenic Policy of Augustus and Agrippa in 27 B. C.", AJPh 93, 190-197. 
Ooteghem, J. VAN (1954), Pompée le Grand, bâtisseur d'Empire, Bruxelles, Académie Royale de Belgique.

Ormerod, H. A. (1924), Piracy in the Ancient World. An Essay in Mediterranean History, Liverpool, The University Press of Liverpool.

OWENS, E. J. (1976), "Increasing Roman Domination of Greece in the years 48-27 B.C.", Latomus 35, 718-729.

PARIGI, C. (2013), “The Romanization of Athens: Greek Identity and Connectivity between Athens and Rome in the $1^{\text {st }}$ Century BC", en SOMA 2012. Identity and Connectivity. Proceedings of the $16^{\text {th }}$ Syposium on Mediterranean Archaeology. Volume I, Bpbardieri, L. et alii (eds.), Oxford, Archaeopress, 447-455.

PARIGI, C. (2016), "The Athenian Walls in the $1^{\text {st }}$ Century BC", en Focus on Fortifications. New Research on Fortifications in the Ancient Mediterranean and the Near East, Frederiksen, R. et alii (eds.), Oxford/Philadelphia, Oxbow Books, 384-396.

POUNDER, R. L. (1983), “A Hellenistic Arsenal in Athens”, Hesperia 52, 233-256.

RAWSON, E. (1985), "Cicero and the Areopagus", Athenaeum 63, 44-67.

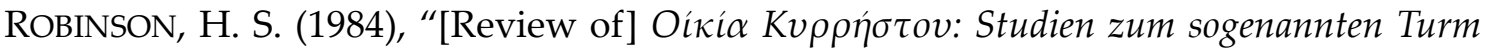
der Winde in Athen, by Joachim of Freeden", AJA 88, 423-425.

RossI, A. (2000), “The Camp of Pompey: Strategy of Representation in Caesar's Bellum Ciuile", CJ 95, 239-256.

SANTANGElO, F. (2007), "Pompey and Religion”, Hermes 135, 228-233.

SCHONKY, M. Y WELWEI, K.-W. (2007), "Archons of Athens", en Brill's New Pauly. Chronologies of the Ancient World. Names, Dates and Dynasties, Eder, W. y Rengel, J. (eds.), Leiden/Boston, Brill, 148-184.

Shackleton BAiley, D. R. (1965), Cicero's Letters to Atticus. Volume III, 51-50 B.C. 94-132 (Books V-VII.9), Cambridge, Cambridge University Press.

ShaCKLETON BAILEY, D. R. (1977), Cicero: Epistulae ad Familiares. Volume I. 62-47 B.C., Cambridge, Cambridge University Press.

SHEAR JR., T. L. (1981), “Athens. From City-State to Provincial Status”, Hesperia 50, 356377.

Stevenson, S. W. (1964), A Dictionary of Roman Coins, Republican and Imperial. London. Seaby.

THOMPSON, L. A. (1941), "Some Athenian 'Cleruchy' Money", Hesperia 10, 199-236.

TOHER, M. (2014), “Herod, Athens and Augustus", ZPE 190, 127-134.

WistRAND, M. (1979), Cicero Imperator. Studies in Cicero's correspondence 51-47 B.C., Göteborg, Acta Universitatis Gothoburgensis.

ZollschaN, L. T. (2007), “The Date of the Fannius Letter: Jos. Ant. 14.233”, JSJ 38, 9-38. 